\title{
PENGUKURAN TINGKAT KEBISINGAN PADA STASIUN KAMAR MESIN DI PABRIK KELAPA SAWIT PT.PERKEBUNAN NUSANTARA IV KEBUN ADOLINA
}

\author{
Cut Ita Erliana dan Aji Suhada Sinaga \\ Jurusan Teknik Industri, Fakultas Teknik, Universitas Malikussaleh, Aceh, Indonesia \\ ${ }^{*}$ Corresponding Author: cutitha@unimal.ac.id
}

\begin{abstract}
Abstrak - Pabrik Kelapa Sawit PTPN IV Kebun Adolina merupakan pabrik yang memproduksi Crude Pulm Oil (CPO). Penelitian ini dilakukan pada lingkungan kerja fisik di stasiun kamar mesin. Ada 11 stasiun pada pabrik kelapa sawit, namun tingkat kebisingan yang paling tidak normal terdapat pada stasiun kamar mesin. Rata-rata tingkat kebisingan pada stasiun kamar mesin mencapai 97dBA. Tingkat kebisingan disebabkan oleh 3 mesin turbin yang bekerja pada stasiun kamar mesin. Titik pengukuran dipetakan hingga terdapat 35 titik pengukuran yang berjarak 2 meter setiap titiknya. Setiap titik pengukuran akan dilakukan pengukuran dan dihitung dengan menggunakan metode ekuivalen. Hasil dari perhitungan tingkat kebisingan pada 35 titik pengukuran dinyatakan tidak baik, dikarenakan seluruh titik pengukuran melewati nilai ambang batas. Tingkat kebisingan pada stasiun kamar mesin perlu dilakukan reduksi. Perusahaan harus memperhatikan seluruh operator pada statsiun kamar mesin dalam hal menggunakan alat pelindung diri dan melakukan check kesehatan pendengaran operator secara rutin, sehingga pekerja terhindar dari cedera serius yang nantinya bisa terjadi.
\end{abstract}

Kata Kunci: Pengukuran Tingkat kebisingan, Tingkat Kebisingan Ekuivalen.

\section{Pendahuluan}

Ergonomi merupakan salah satu disiplin ilmu teknik industri. Ergonomi merupakan suatu ilmu yang mempelajari tentang keterbatasan dan kemampuan manusia dalam melakukan pekerjaanya, sehingga tidak terlepas dari sebuah aturan kerja. Ergonomi mempelajari tentang lingkungan kerja fisik, antropometri, beban kerja, penyempurnaan produk dan cara kerja yang baik. Setiap melakukan suatu pekerjaan, produktifitas serta efektifitas pekerja akan dipengaruhi oleh beberapa factor, dan salah satunya adalah lingkungan kerja fisik [1] [2].

Lingkungan kerja fisik merupakan faktor yang paling mempengaruhi pekerja dalam melakukan pekerjaannya. Lingkungan kerja fisik yang baik akan menimbulkan rasa aman, nyaman dan tenang bagi pekerja, sehingga dapat meningkatkan kinerja. Ada beberapa faktor yang memepengaruhi lingkungan kerja fisik, seperti kebisingan, sirkulasi udara, pencahayaan, bau, getaran, suhu dan lain-lain. Kebisingan adalah salah satu faktor yang selalu berpengaruh terhadap kinerja dan hampir seluruh pabrik merasakannya [3].
Pabrik Kelapa Sawit (PKS) PT. Perkebunan Nusantara IV Kebun Adolina memiliki beberapa stasiun kerja dalam memproses kelapa sawit menjadi Crude Palm Oil (CPO). Stasiun kerja dalam proses pengolahan ada timbangan, sortasi, loading ramp, stasiun perebusan, stasiun penembah, stasiun kempa, stasiun pemurnian minyak, stasiun biji, kamar mesin, katel uap dan water treatment. Stasiun kamar mesin adalah stasiun pengatur tenaga untuk menjalankan semua mesin didalam sebuah pabrik. Jika terjadinya kerusakan pada kamar mesin, maka pabrik tidak akan bisa melakukan apa-apa. Stasiun kamar mesin terdapat beberapa mesin yang digunakan, seperti turbin, genset, Back Pressure Vassel (BPV) dan main switch distribution board. Stasiun kamar mesin memiliki 6 operator yang terbagi menjadi dua shift dan memiliki luas $216 \mathrm{~m}^{2}$. Selama pengukuran berlangsung, mesin turbin adalah mesin yang paling mengganggu lingkungan kerja. Mesin turbin pada stasiun kamar mesin berjumlah 3 unit dengan tingkat kebisingan rata-rata 97 dBA [4]. 


\section{Tinjauan Pustaka}

Pada umumnya, setiap organisasi baik yang berskala besar, menengah, maupun kecil, semuanya akan berinteraksi dengan lingkungan di mana organisasi atau perusahaan tersebut berada. Lingkungan itu sendiri mengalami perubahan parubahan sehingga, organisasi atau perusahaan yang bisa bertahan hidup adalah organisasi yang bias menyesuaikan diri dengan perubahan lingkungan. Sebaliknya, organisasi akan mengalami masa kehancuran apabila organisasi tersebut tidak memperhatikan perkembangan dan perubahan lingkungan disekitarnya. Lingkungan kerja adalah tempat di mana karyawan melakukan aktifitas setiap harinya. Lingkungan kerja yang kondusif memberikan rasa aman dan memungkinkan karyawan untuk dapat bekerja optimal. Lingkungan kerja dapat mempengaruhi emosional karyawan. Jika karyawan menyenangi lingkungan kerjanya maka karyawan tersebut akan betah di tempat kerjanya, melakukan aktifitasnya sehingga waktu kerja dipergunakan secara efektif. Produktifitas akan tinggi dan prestasi kerja karyawan juga tinggi [5].

Lingkungan kerja dapat diartikan sebagai kekuatankekuatan yang mempengaruhi, baik secara langsung maupun tidak langsung terhadap kinerja organisasi atau perusahaan. Menurut Sedarmayati bahwa lingkungan kerja adalah keseluruhan alat perkakas dan bahan yang dihadapi, lingkungan sekitarnya dimana seseorang bekerja, metode kerjanya, serta pengaturan kerjanya, baik sebagai perseorangan maupun sebagai kelompok. Sementara itu, menurut Bambang Kussrianto bahwa lingkungan kerja merupakan salah satu faktor yang mempengaruhi kinerja seorang karyawan.

Pengertian lain tentang lingkungan kerja bahwa lingkungan kerja merujuk pada lembaga-lembaga atau kekuatan-kekuatan yang berada di dalam maupun di luar organisasi tersebut dan secara potensial mempengaruhi kinerja organisasi itu. lingkungan kerja adalah proses kerja dimana lingkungan saling berinteraksi menurut pola tertentu, dan masing-masing memiliki karakteristik dan/ atau nilai-nilai tertentu mengenai organisasi yang tidak akan lepas dari pada lingkungan dimana organisasi itu berada, dan manusianya yang merupakan sentrum segalanya. Sesuai dengan pendapat yang telah dikemukakan di atas, maka dapat disimpulkan bahwa lingkungan kerja adalah komponen-komponen yang merujuk pada lembaga atau kekuatan yang berinteraksi langsung maupun tidak langsung menurut pola tertentu mengenai organisasi atau perusahaan yang tidak akan lepas dari pada lingkungan dimana organisasi atau perusahaan itu berada [6] [7].

\section{Lingkungan Kerja Fisik}

Lingkungan kerja fisik dapat diartikan semua keadaan yang ada di sekitar tempat kerja, yang dapat mempengaruhi kinerja karyawan. lingkungan kerja fisik yaitu semua keadaan berbentuk fisik yang terdapat disekitar tempat kerja dimana dapat mempengaruhi kerja karyawan baik secara langsung maupun tidak langsung. Lingkungan kerja fisik adalah kondisi fisik dalam perusahaan disekitar tempat kerja, seperti sirkulasi udara, warna tembok, keamanan, ruang gerak dan lainlain.

Lingkungan kerja fisik adalah salah satu unsur yang harus digunakan perusahaan sehingga dapat menimbulkan rasa aman, tentram dan dapat meningkatkan hasil kerja yang baik untuk peningkatan kinerja karyawan. Beberapa faktor yang mempengaruhi lingkungan kerja fisik meliputi warna, kebersihan, sirkulasi udara, penerangan dan keamanan. Faktor-faktor yang mempengaruhi terbentuknya suatu lingkungan kerja diantaranya adalah temperatur, kelembaban, sirkulasi udara, pencahayaan, kebisingan, getaran mekanis dan keamanan. lingkungan kerja non fisik adalah semua keadaan yang terjadi yang berkaitan dengan hubungan kerja, baik dengan atasan maupun dengan sesama rekan kerja, ataupun dengan bawahan. Jadi, dapat disimpulkan bahwa dalam menciptakan suasana lingkungan kerja yang baik yaitu dengan menciptakan hubungan/interaksi antar karyawan yang baik pula agar suasana kerja yang tercipta akan lebih nyaman dan harmonis sehingga karyawan akan lebih semangat dalam meningkatkan kinerja [8].

\section{Faktor-Faktor Lingkungan Kerja Fisik}

Terdapat beberapa faktor yang mempengaruhi lingkungan kerja adalah sebagai berikut [9]:

1. Penerangan. Penerangan adalah cukupnya sinar yang masuk kedalam ruang kerja, masing masing karyawan perusahaan. Penerangan yang ada harus sesuai dengan kebutuhan, tidak terlalu terang tetapi juga tidak terlalu gelap, dengan sistem penerangan yang baik diharapkan karyawan akan menjalankan tugasnya dengan lebih teliti, sehingga kesalahan karyawan dalam bekerja dapat diperkecil.

2. Suhu udara. Temperatur udara atau suhu udara terlalu panas bagi karyawan akan dapat menjadi penyebab penurunnya kepuasan kerja para karyawan sehingga akan menimbulkan kesalahankesalahan pelaksanaan proses produksi.

3. Suara bising. Karyawan memerlukan suasana yang dapat mendukung konsentrasi dalam bekerja suasana bising yang bersumber dari mesin-mesin pabrik maupun dari kendaraan umum akan dapat menganggu konsentrasi karyawan dalam bekerja.

4. Ruang gerak. Manajemen perusahaan perlu untuk memperhatikan ruang gerak yang memadai dalam perusahaan, agar karyawan dapat leluasa bergerak dengan baik, terlalu sempitnya ruang gerak yang tersedia akan mengakibat-kan karyawan tidak dapat bekerja dengan baik. Karena itu, manajemen perusahaan tentunya harus dapat menyusun perencanaan yang tepat untuk runag gerak yang dari masing-masing karyawan.

5. Keamanan kerja. Keamanan kerja merupakan faktor yang sangat penting yang diperhatikan oleh perusahaan. Kondisi kerja yang aman akan 
membuat karyawan tenang dalam bekerja sehingga meningkatkan produktivitas karyawan.

\section{Pengertian Kebisingan}

Suara adalah sensasi yang sewaktu vibrasi longitudinal dari molekul-molekul udara, yang berupa gelombang mencapai membrana timpani dari telinga [10], menyatakan bahwa dalam konteks keselamatan dan kesehatan kerja, pembahasan suara (sound) agak berbeda dibandingkan pembahasan-pembahasan suara dalam ilmu fisika murni maupun fisika terapan. Keselamatan dan Kesehatan Kerja (K3) [11], menyatakan bahwa suara lebih terfokus pada potensi gelombang suara sebagai salah satu bahaya lingkungan potensial bagi pekerja di tempat kerja beserta teknik-teknik pengendaliannya.

Kebisingan adalah bunyi yang tidak diinginkan dari usaha atau kegiatan dalam tingkat dan waktu dan tertentu yang dapat menimbulkan gangguan kesehatan manusia dan kenyamanan lingkungan. Bunyi atau suara didengar sebagai rangsangan pada sel saraf pendengaran dalam telinga oleh gelombang longitudinal yang ditimbulkan getaran dari sumber bunyi atau suara dan gelombang tersebut merambat melalui media udara atau penghantar lainnya, dan manakala bunyi atau suara tersebut tidak dikehendaki oleh karena mengganggu atau timbul diluar kemauan orang yang bersangkutan, maka bunyi-bunyian atau suara demikian dinyatakan sebagai kebisingan. Kebisingan didefinisikan sebagai bunyi yang tidak dikehehndaki. Bising menyebabkan berbagai gangguan terhadap tenaga kerja, seperti gangguan fisiologis, gangguan psikologis, gangguan komunikasi dan ketulian, atau ada yang menggolongkan gangguannya berupa gangguan pendengaran, misalnya gangguan terhadap pendengaran dan gangguan pendengaran seperti komunikasi terganggu, ancaman bahaya keselamatan, menurunnya performa kerja, kelelahan dan stres [12].

Jenis pekerjaan yang melibatkan paparan terhadap kebisingan antara lain pertambangan, pembuatan terowongan, mesin berat, penggalian (pengeboman, peledakan), mesin tekstil, dan uji coba mesin jet. Bising dapat didefinisikan sebagai bunyi yang tidak disukai, suara yang mengganggu atau bunyi yang menjengkelkan. Suara bising adalah suatu hal yang dihindari oleh siapapun, lebih-lebih dalam melaksanakan suatu pekerjaan, karena konsentrasi pekerja akan dapat terganggu. Dengan terganggunya konsentrasi ini maka pekerjaan yang dilakukkan akan banyak timbul kesalahan ataupun kerusakan sehingga akan menimbulkan kerugian [13].

Frekuensi kebisingan juga penting dalam menentukan perasaan yang subjektif, namun bahaya di area kebisingan tergantung pada frekuensi bising yang ada. Tuli dapat disebabkan oleh tempat kerja yang terlalu bising. Yang dimaksud dengan "tuli akibat kerja" yaitu gangguan pendengaran parsial atau total pada satu atau kedua telinga yang didapat di tempat kerja. Termasuk dalam hal ini adalah trauma akustik dan tuli akibat kerja karena bising. Industri yang menghasilkan pajanan 90 dBA atau lebih ditemukan pada pabrik tekstil, penggergajian kayu, industri mebel, produk-produk yang menggunakan bahan baku logam, dan industri otomotif [14].

\section{Jenis-Jenis Kebisingan}

Menurut kebisingan di tempat kerja diklasifikasikan ke dalam dua jenis golongan, yaitu [15]:

1. Kebisingan yang tetap (steady noise) dipisahkan lagi menjadi dua jenis, yaitu :

a. Kebisingan dengan frekuensi terputus (discrete frequency noise). Kebisingan ini merupakan nada-nada murni pada frekuensi yang beragam. Contohnya suara mesin, suara kipas dan sebagainya.

b. Kebisingan tetap (Broad band noise), kebisingan dengan rekuensi terputus dan Brod band noise sama-sama digolongkan sebagai kebisingan tetap (steady noise).

Perbedaannya adalah broad band noise terjadi pada frekuensi yang lebih bervariasi.

2. Kebisingan tidak tetap (unsteady noise) dipisahkan lagi menjadi tiga jenis, yaitu :

a. Kebisingan fluktuatif (fluctuating noise), kebisingan yang selalu berubah-ubah selama rentang waktu tertentu.

b. Intermitent noise, kebisingan yang terputusputus dan besarnya dapat berubah-ubah. Contoh kebisingan lalu lintas.

c. Kebisingan impulsif (Impulsive noise), kebisingan ini dihasilkan oleh suara-suara berintensitas tinggi (memekakkan telinga) dalam waktu relatif singkat, misalnya suara ledakan senjata dan alatalat sejenisnya.

Tingkat kebisingan dapat diklasifikasikan berdasarkan intensitas yang diukur dengan satuan decibel ( $\mathrm{dB}$ ) seperti pada Tabel 1 berikut.

Tabel 1. Tingkat dan Sumber Bunyi pada Skala Kebisingan Tertentu

\begin{tabular}{|c|l|c|}
\hline $\begin{array}{c}\text { Tingkat Bising } \\
\mathbf{d B}(\mathbf{A})\end{array}$ & Sumber Bunyi & $\begin{array}{c}\text { Skala } \\
\text { Intensitas }\end{array}$ \\
\hline $0-20$ & $\begin{array}{l}\text { Gemerisik } \\
\text { daun Suara } \\
\text { gemerisik }\end{array}$ & Sangat Tenang \\
\hline $20-40$ & $\begin{array}{l}\text { Perpustakaan, } \\
\text { Percakapan }\end{array}$ & Tenang \\
\hline $40-60$ & $\begin{array}{l}\text { Radio pelan, } \\
\text { Percakapan } \\
\text { keras Rumah, } \\
\text { gaduh Kantor }\end{array}$ & Sedang \\
\hline $60-80$ & $\begin{array}{l}\text { Perusahaan, } \\
\text { Radio keras, } \\
\text { Jalan }\end{array}$ & Keras \\
\hline $80-100$ & $\begin{array}{l}\text { Peluit polisi, } \\
\text { Jalan raya }\end{array}$ & Sangat Keras \\
\hline
\end{tabular}




\begin{tabular}{|c|l|c|}
\hline & $\begin{array}{l}\text { Pabrik tekstil, } \\
\text { Pekerjaan } \\
\text { Mekanis }\end{array}$ & \\
\hline \multirow{2}{*}{$100-120$} & $\begin{array}{l}\text { Ruang ketel, } \\
\text { Mesin turbin } \\
\text { uap, Mesin } \\
\text { diesel besar, } \\
\text { Kereta bawah } \\
\text { tanah }\end{array}$ & $\begin{array}{c}\text { Sangat Amat } \\
\text { Keras }\end{array}$ \\
\hline+120 & $\begin{array}{l}\text { Ledakan bom, } \\
\text { Mesin jet } \\
\text { Mesin roket }\end{array}$ & Meulikan \\
\hline
\end{tabular}

\section{Pengukuran Kebisingan}

Untuk mengukur kebisingan di lingkungan kerja dapat dilakukan dengan menggunakan alat Sound Level Meter. Sebelumnya, intensitas bunyi adalah jumlah energi bunyi yang menembus tegak lurus bidang per detik. Metode pengukuran akibat kebisingan di lokasi kerja, yaitu [16]:

1. Pengukuran dengan titik sampling

Pengukuran ini dilakukan bila kebisingan diduga melebihi ambang batas hanya pada satu atau beberapa lokasi saja. Pengukuran ini juga dapat dilakukan untuk mengevalusai kebisingan yang disebabkan oleh suatu peralatan sederhana, misalnya kompresor/generator. Jarak pengukuran dari sumber harus dicantumkan, misal 3 meter dari ketinggian 1 meter. Selain itu juga harus diperhatikan arah mikrofon alat pengukur yang digunakan.
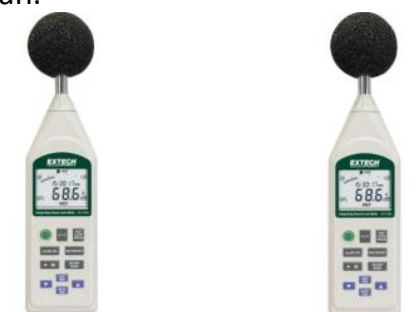

\section{Gambar 1. Sound Level Meter}

2. Pengukuran dengan peta kontur

Pengukuran dengan membuat peta kontur sangat bermanfaat dalam mengukur kebisingan, karena peta tersebut dapat menentukan gambar tentang kondisi kebisingan dalam cakupan area. Pengukuran ini biasanya dibuat kode pewarnaan untuk menggambarkan keadaan kebisingan, warna hijau untuk kebisingan dengan intensitas di bawah 85 $\mathrm{dBA}$, warna oranye untuk tingkat kebisingan yang tinggi di atas $90 \mathrm{dBA}$, warna kuning untuk kebisingan dengan intensitas antara 85-90 dBA.

3. Pengukuran dengan aplikasi handphone

Pengukuran dengan menggunakan aplikasi handphone tidak berbeda dengan menggunakan alat sound level meter. Perbedaan aplikasi dengan alat sound level meter hanya software dan hardware, sedangkan penggunaannya tidak jauh berbeda. Penggunaan aplikasi harus dilakukan kalibrasi agar tingkat keakuratannya tidak berbeda dengan alat sesungguhnya. Kalibrasi bisa dilakukan dengan menambah atau mengurangi desibel yang tertera pada layar. Penambahan atau pengurangan desibel pada aplikasi tergantung pada alat Sound Level Meter yang digunakan. Menurut PPI KIM, dalam kaibrasi alat ukur kebisingan dengan aplikasi handphone harus menambahkan 0-6 dBA sesuai dengan alat sound level meter yang dibandingkan. Caranya meletakkan alat Sound Level Meter bersebelahan dengan handphone. Ketika angka yang ditunjukkan pada layar handphone berbeda dengan yang ditunjukkan pada alat Sound Level Meter. Buka menu pengaturan pada aplikasi, lalu klik kalibrasi dan tambahkan sesuai perbedaannya.

\section{Nilai Ambang Batas Kebisingan}

NAB menurut Kepmenaker No. per-51/ MEN/ 1999, ACGIH, 2008 dan SNI 16-7063-2004 adalah 85dB untuk pekerja yang sedang bekerja selama 8 jam perhari atau 40 jam perminggu. Nilai ambang batas untuk kebisingan di tempat kerja adalah intensitas tertinggi dan merupakan rata-rata yang masih diterima tenaga kerja tanpa menghilangkan daya dengar yang tetap untuk waktu terus-menerus tidak lebih dari 8 jam sehari atau 40 jam perminggu.

Adapun tingkat kebisingan dan maksimal pekerja dalam pemejaan dalam satu hari menurut Kepmenaker No.Kep-51/MEN/1999 dapat dilihat pada tabel 2 sebagai berikut:

Tabel 2. NAB Kebisingan Berdasarkan Kepmenaker No.Kep-51/MEN/1999

\begin{tabular}{|c|c|c|}
\hline No & $\begin{array}{c}\text { Tingkat Kebisingan } \\
\text { (dBA) }\end{array}$ & Pemajan Harian \\
\hline 1 & 82 & 16 jam \\
\hline 2 & 83,3 & 12 jam \\
\hline 3 & 85 & 8 jam \\
\hline 4 & 88 & 4 jam \\
\hline 5 & 91 & 2 jam \\
\hline 6 & 94 & 1 jam \\
\hline 7 & 97 & 30 menit \\
\hline 8 & 100 & 15 menit \\
\hline 9 & 103 & 7,5 menit \\
\hline 10 & 106 & 3,5 menit \\
\hline 11 & 109 & 1,88 menit \\
\hline
\end{tabular}

Catatan: Tidak boleh terpapar lebih dari $140 \mathrm{~dB}$, walaupun sesaat

Sumber: Menaker.1999

Kebisingan di atas $80 \mathrm{~dB}$ dapat menyebabkan kegelisahan, tidak enak badan, kejenuhan mendengar, sakit lambung, dan masalah peredaran darah. Kebisingan yang berlebihan dan berkepanjangan terlihat dalam masalah-masalah kelainan seperti penyakit jantung, tekanan darah tinggi, dan luka perut. Pengaruh kebisingan yang merusak pada efisiensi kerja dan 
produksi telah dibuktikan secara statistik dalam beberapa bidang industri [17].

\section{Metodelogi Penelitian}

Metode pengumpulan data yang digunakan dalam penelitian ini sebagai berikut:

1. Data primer merupakan data yang diperoleh langsung dari sumber yang diamati, dengan cara sebagai berikut:

a. Observasi, yaitu melakukan pengamatan secara langsung pada objek penelitian dan mengumpulkan data yang diperlukan. Obeservasi yang dilakukan adalah mengukur tingkat kebisingan pada stasiun kamar mesin. Pengukuran dilakukan selama 5 hari dan 8 waktu pengukuran setiap harinya. Pengukuran dilakukan dengan aplikasi handphone bernama decibel meter setiap jarak sekitar 2 meter.

b. Wawancara, yaitu dengan mengajukan serangkaian pertanyaan kepada pekerja yang dibutuhkan dalam penelitian, yang berkaitan dengan hal-hal distasiun kamar mesin pada Pabrik Kelapa Sawit PTPN IV Kebun Adolina Perbaungan.

2. Data sekunder merupakan data yang diperoleh bukan dari informasi langsung perusahaan, melainkan dari sumber-sumber lain seperti:

Penelitian Pustaka (Library Research) yaitu, pengumpulan data yang bersifat teoritis melalui buku-buku literatur dan journal yang relevan dengan topik dan masalah.

\section{Pengumpulan Data}

Titik pengukuran tingkat kebisingan dilakukan pada 35 titik dapat dilihat pada gambar sebagai berikut:

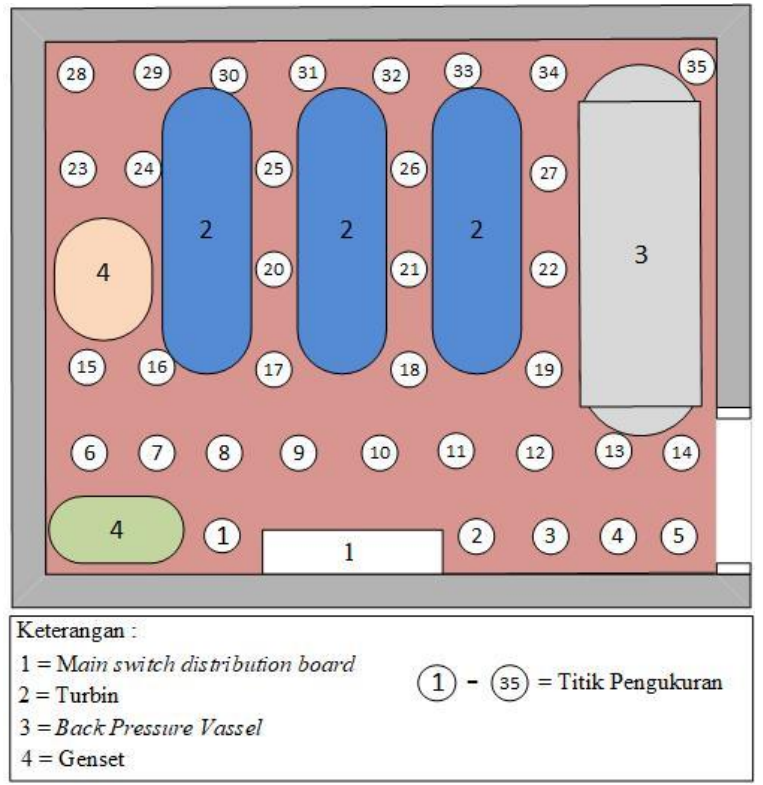

Gambar 2. Layout Pengukuran pada Kamar Mesin

\section{Hasil Dan Pembahasan}

\section{Tingkat Kebisingan Ekuivalen (Leq)}

Berdasarkan metode perhitungan kebisingan KEP48/MENLH/11/1996 bahwa tingat kebisingan ekuivalen (Leq) sebagai berikut.

Data tingkat kebisingan pada titik 1-35 pukul 07.00 Fraksi pengukuran hari pertama titik 1-35, yaitu 1/35

Maka,

$$
\text { Leq }=10 \log \left\{\frac{1}{35} 10^{0,1 \times 93}+\frac{1}{35} 10^{0,1 \times 95}+\ldots+\frac{1}{35} 10^{0,1 \times 98}\right\}=97,77
$$

Hasil rekapitulasi perhitungan Leq hari pertama sampai kelima dapat dilihat pada Tabel sebagai berikut:

Tabel 3. Hasil Rekapitulasi Perhitungan Leq

\begin{tabular}{|c|c|c|c|c|c|}
\hline \multirow{2}{*}{ Waktu } & \multicolumn{5}{|c|}{ Hasil Leq (dBA) } \\
\cline { 2 - 6 } & Hari 1 & Hari 2 & Hari 3 & Hari 4 & Hari 5 \\
\hline 07.00 & 97,77 & 97,84 & 97,61 & 97,71 & 97,97 \\
\hline 09.00 & 97,79 & 97,71 & 98,13 & 97,80 & 97,91 \\
\hline 11.00 & 97,67 & 97,68 & 97,92 & 97,92 & 97,73 \\
\hline 13.00 & 97,75 & 97,57 & 97,90 & 98,01 & 98,04 \\
\hline 15.00 & 97,50 & 97,75 & 97,96 & 97,58 & 98,12 \\
\hline 17.00 & 98,48 & 98,23 & 98,24 & 98,45 & 98,27 \\
\hline 19.00 & 98,46 & 98,32 & 98,39 & 98,48 & 98,50 \\
\hline 21.00 & 98,76 & 98,63 & 98,33 & 98,46 & 98,23 \\
\hline
\end{tabular}

\section{Tingkat Kebisingan Ekuivalen Setiap Titik Pengukuran}

Data tingkat kebisingan pada setiap titik dan waktu pengukuran selama lima hari lebih representatif diwakili oleh tingkat kebisingan ekuivalen. Adapun hasil dari perhitungan tingkat kebisingan ekuivalen pada setiap titik pengukuran adalah sebagai berikut

Pada Titik 1 Jam 07.00

- $\quad$ L(Hari 1): 93

- L(Hari 2): 94

- L(Hari 3): 94

- $\quad$ L(Hari 4): 95

- L(Hari 5): 93

Fraksi pengukuran selama 5 hari, yaitu: $1 / 5$ Maka,

$$
\text { Leq }=10 \text { Log }\left\{\begin{array}{c}
\frac{1}{5} 10^{0,1 \times 93}+\frac{1}{5} 10^{0,1 \times 94} \\
+\frac{1}{5} 10^{0,1 \times 94}+\frac{1}{5} 10^{0,1 \times 95}+\frac{1}{5} 10^{0,1 \times 93}
\end{array}\right\}=93,87
$$

Perhitungan yang sama dilakukan untuk titik ke 2 sampai ke 35 di setiap waktunya. Rekapitulasi hasil perhitungan tingkat kebisingan ekuivalen pada setiap titik pengukuran dapat dilihat pada Tabel sebagai berikut:

Tabel 4. Rekapitulasi hasil tingkat kebisingan setiap titik pengukuran

\begin{tabular}{|c|c|c|c|c|c|c|c|c|}
\hline \multirow{2}{*}{$\begin{array}{c}\text { Ti } \\
\text { tik }\end{array}$} & \multicolumn{7}{|c|}{ Tingkat Kebisingan Ekuivalen (dBA) } \\
\cline { 2 - 9 } & \multicolumn{8}{|c|}{ Waktu } \\
\cline { 2 - 9 } & $\mathbf{0 7 . 0 0}$ & $\mathbf{0 9 . 0 0}$ & $\mathbf{1 1 . 0 0}$ & $\mathbf{1 3 . 0 0}$ & $\mathbf{1 5 . 0 0}$ & $\mathbf{1 7 . 0 0}$ & $\mathbf{1 9 . 0 0}$ & $\mathbf{2 1 . 0 0}$ \\
\hline 1 & 93.87 & 94.05 & 94.05 & 94.52 & 93.05 & 96.02 & 94.95 & 95.43 \\
\hline 2 & 94.26 & 93.95 & 94.86 & 93.82 & 93.67 & 95.05 & 95.72 & 96.09 \\
\hline 3 & 93.72 & 94.71 & 94.52 & 94.31 & 94.52 & 95.44 & 96.2 & 95.72 \\
\hline 4 & 93.72 & 94.6 & 94.63 & 93.63 & 94.42 & 95.36 & 95.72 & 95.01 \\
\hline
\end{tabular}




\begin{tabular}{|c|c|c|c|c|c|c|c|c|}
\hline 5 & 94.01 & 94.52 & 93.76 & 94.23 & 94.9 & 95.56 & 95.13 & 95.67 \\
\hline 6 & 94.2 & 93.48 & 94.23 & 94.26 & 94.15 & 96.03 & 95.92 & 93.68 \\
\hline 7 & 94.05 & 92.68 & 93.26 & 94.79 & 93.47 & 96.22 & 93.63 & 95.23 \\
\hline 8 & 94.43 & 93.63 & 93.15 & 93.83 & 93.52 & 96.09 & 94.61 & 95.39 \\
\hline 9 & 94.26 & 94.63 & 93.36 & 93.68 & 93.43 & 95.09 & 95.52 & 95.01 \\
\hline 10 & 94.32 & 93.86 & 94.36 & 93.82 & 94.43 & 96.47 & 95.83 & 95.95 \\
\hline 11 & 94.17 & 94.15 & 95.11 & 94.31 & 95.01 & 94.52 & 96.43 & 95.83 \\
\hline 12 & 94 & 94.63 & 94.98 & 94.68 & 94.47 & 94.26 & 95.61 & 94.97 \\
\hline 13 & 94.19 & 93.32 & 94.63 & 94.75 & 94.39 & 94.9 & 94.68 & 95.56 \\
\hline 14 & 95.45 & 94.83 & 95.1 & 94.35 & 93.97 & 94.97 & 95.44 & 95.95 \\
\hline 15 & 97.09 & 95.75 & 97.2 & 95.62 & 96.2 & 95.63 & 95.72 & 95.72 \\
\hline 16 & 99.04 & 99.36 & 98.4 & 99.45 & 99.76 & 98.31 & 99.34 & 99.95 \\
\hline 17 & 99.86 & 98.68 & 99.86 & 98.82 & 98.68 & 98.26 & 98.43 & 98.83 \\
\hline 18 & 99.26 & 99.68 & 100.1 & 98.93 & 99.86 & 99.05 & 99.32 & 101 \\
\hline 19 & 100.4 & 98.86 & 98.05 & 98.32 & 99.47 & 100.4 & 98.47 & 100.6 \\
\hline 20 & 100.1 & 99.52 & 98.9 & 99.83 & 99.26 & 100 & 99.65 & 100.9 \\
\hline 21 & 99.36 & 100.3 & 99.55 & 100.3 & 99.86 & 98.87 & 100.5 & 101.5 \\
\hline 22 & 99.64 & 99.8 & 98.22 & 99.52 & 99.68 & 99.05 & 100.1 & 99.79 \\
\hline 23 & 99.12 & 99.98 & 99.43 & 99.29 & 98.55 & 99.09 & 99.77 & 98.36 \\
\hline 24 & 98.97 & 99.55 & 99.01 & 100.1 & 99.55 & 101.4 & 101.1 & 99.87 \\
\hline 25 & 98.64 & 99.48 & 99.1 & 97.9 & 99.26 & 100.1 & 99.15 & 98.83 \\
\hline 26 & 98.75 & 100.4 & 99.2 & 100.0 & 99.44 & 101.1 & 100.4 & 100.3 \\
\hline 27 & 99.01 & 100.6 & 99.68 & 100.3 & 99.68 & 100.1 & 100.3 & 100.2 \\
\hline 28 & 99.35 & 98.68 & 98.95 & 99.64 & 97.72 & 101 & 99.36 & 99.52 \\
\hline 29 & 98.86 & 98.62 & 99.98 & 100.3 & 99.07 & 97.82 & 98.68 & 99.63 \\
\hline 30 & 98.45 & 97.56 & 99.04 & 98.18 & 99.09 & 99.23 & 100.5 & 98.43 \\
\hline 31 & 99.52 & 100 & 99.1 & 100 & 99.52 & 98.95 & 99.91 & 100.2 \\
\hline 32 & 99.56 & 98.36 & 99.64 & 99.19 & 100.2 & 99.68 & 99.86 & 100.1 \\
\hline 33 & 98.86 & 99.26 & 99.64 & 99.86 & 98.59 & 100.5 & 100.1 & 99.19 \\
\hline 34 & 97.52 & 99.91 & 98.68 & 97.95 & 98.94 & 98.26 & 99.95 & 99.51 \\
\hline 35 & 99.01 & 99.11 & 99.13 & 98.15 & 98.9 & 100 & 100.1 & 99.43 \\
\hline & & & & & & & & \\
\hline
\end{tabular}

\section{Tingkat Kebisingan Ekuivalen Total}

Sesuai ketentuan dari menteri negara lingkungan hidup, data tingkat kebisingan ekuivalen pada setiap titik dan waktu diklasifikasi dalam 2 jenis, tingkat kebisingan siang hari dan malam hari. Interval waktu sesuai peraturan KEP48/MENLH/11/1996 dengan waktu pengukuran dilakukan selama selama 16 jam (LS) pada selang waktu 06.00-22.00. Perhitungan tingkat kebisingan ekuivalen pada jam 07.00, 09.00, 11.00, 13.00, $15.00,17.00,19.00$ dan 21.00. Untuk menghitung tingkat kebisingan pada titik 1 sebagai berikut:

$$
\begin{array}{ll}
\text { - } & \text { Leq }(07.00): 93,87 \mathrm{dBA} \\
\text { - } & \text { Leq }(09.00): 94,05 \mathrm{dBA} \\
\text { - } & \text { Leq }(11.00): 94,05 \mathrm{dBA} \\
\text { - } & \text { Leq }(13.00): 94,52 \mathrm{dBA} \\
\text { - } & \text { Leq }(15.00): 93,05 \mathrm{dBA} \\
\text { - } & \text { Leq }(17.00): 96,02 \mathrm{dBA} \\
\text { - } & \text { Leq }(19.00): 94,95 \mathrm{dBA} \\
\text { - } & \text { Leq }(21.00): 95,43 \mathrm{dBA} \\
\hline &
\end{array}
$$

$\mathrm{f1}=$ fraksi waktu mewakili jam 06.00-08.00 (yaitu = 2/16) $\mathrm{f} 2=$ fraksi waktu mewakili jam 08.00-10.00 (yaitu $=2 / 16$ )

$\mathrm{f3}=$ fraksi waktu mewakili jam 10.00-12.00 (yaitu $=2 / 16$ )

$\mathrm{f} 4=$ fraksi waktu mewakili jam 12.00-14.00 (yaitu $=2 / 16$ )

$\mathrm{f5}=$ fraksi waktu mewakili jam 14.00-16.00 (yaitu $=2 / 16$ )

f6 = fraksi waktu mewakili jam 16.00-18.00 (yaitu $=2 / 16$ )

$\mathrm{f7}=$ fraksi waktu mewakili jam 18.00-20.00 (yaitu $=2 / 16$ )

$\mathrm{f} 8=$ fraksi waktu mewakili jam 20.00-22.00 (yaitu $=2 / 16$ )

Maka, Leq $=10 \log \left\{\begin{array}{c}\frac{2}{16} 10^{0,1 \times 93,87}+\frac{2}{16} 10^{0,1 \times 94,05}+\frac{2}{16} 10^{0,1 \times 94,05} \\ +\frac{2}{16} 10^{0,1 \times 94,52}+\frac{2}{16} 10^{0,1 \times 93,05} \\ +\frac{2}{16} 10^{0,1 \times 96,02}+\frac{2}{16} 10^{0,1 \times 94,95}+\frac{2}{16} 10^{0,1 \times 95,43}\end{array}\right\}=94,58$

Manuscript received September24th, 2020, revised October 1st, 2020
Dari hasil perhitungan diatas, rekapitulasi tingkat kebisingan satu hari pada setiap titik pengukuran dapat dilihat pada Tabel sebagai berikut:

Tabel 5. Rekapitulasi Tingkat Kebisingan Total \begin{tabular}{|c|c|c|c|}
\hline Titik & Ls (dBA) & NAB (dBA) & Reduksi (dBA) \\
\hline
\end{tabular}

\begin{tabular}{|c|c|c|c|}
\hline 1 & 94.58 & 85 & 9.58 \\
\hline 2 & 94.76 & 85 & 9.76 \\
\hline 3 & 94.96 & 85 & 9.96 \\
\hline 4 & 94.69 & 85 & 9.69 \\
\hline 5 & 94.77 & 85 & 9.77 \\
\hline 6 & 94.59 & 85 & 9.59 \\
\hline 7 & 94.31 & 85 & 9.31 \\
\hline 8 & 94.44 & 85 & 9.44 \\
\hline 9 & 94.44 & 85 & 9.44 \\
\hline 10 & 94.99 & 85 & 9.99 \\
\hline 11 & 95.01 & 85 & 10.01 \\
\hline 12 & 94.73 & 85 & 9.73 \\
\hline 13 & 94.59 & 85 & 9.59 \\
\hline 14 & 95.05 & 85 & 10.05 \\
\hline 15 & 96.16 & 85 & 11.16 \\
\hline 16 & 99.24 & 85 & 14.24 \\
\hline 17 & 98.97 & 85 & 13.97 \\
\hline 18 & 99.70 & 85 & 14.70 \\
\hline 19 & 99.42 & 85 & 14.42 \\
\hline 20 & 99.81 & 85 & 14.81 \\
\hline 21 & 100.11 & 85 & 15.11 \\
\hline 22 & 99.51 & 85 & 14.51 \\
\hline 23 & 99.23 & 85 & 14.23 \\
\hline 24 & 100.03 & 85 & 15.03 \\
\hline 25 & 99.09 & 85 & 14.09 \\
\hline 26 & 100.01 & 85 & 15.01 \\
\hline 27 & 100.04 & 85 & 15.04 \\
\hline 28 & 99.37 & 85 & 14.37 \\
\hline 29 & 99.19 & 85 & 14.19 \\
\hline 30 & 98.89 & 85 & 13.89 \\
\hline 31 & 99.67 & 85 & 14.67 \\
\hline 32 & 99.61 & 85 & 14.61 \\
\hline 33 & 99.55 & 85 & 14.55 \\
\hline 34 & 98.92 & 85 & 13.92 \\
\hline 35 & 99.27 & 85 & 14.27 \\
\hline
\end{tabular}

Berdasarkan tabel rekapitulasi tingkat kebisingan ekuivalen total, maka seluruh titik kebisingan melewati Nilai Ambang Batas (NAB) dan perlu dilakukan reduksi. Karena seluruh kebisingan setiap titik perlu dilakukan reduksi, maka kebisingan di stasiun kamar mesin PKS PTPN IV Kebun Adolina dinyatakan tidak baik dan perlu dilakukan perhatian lebih terhadap lingkungan kerja dan pekerja.

\section{Pemetaan Kebisingan Ruang (Noise Mapping)}

Deskripsi arah/pola penyebaran kebisingan ruang dapat dilakukan dengan membuat peta kebisingan ruangan dengan bantuan Software Surfer. Jumlah titik kebisingan yang diambil adalah 35 titik sebanyak 5 hari waktu pengukuran. Pemetaan kebisingan ruang dibuat 
setiap waktu pengukuran kebisingan total pada stasiun kamar mesin. Koordinat titik pengukuran di setiap titik pengukuran dapat dilihat pada gambar berikut.

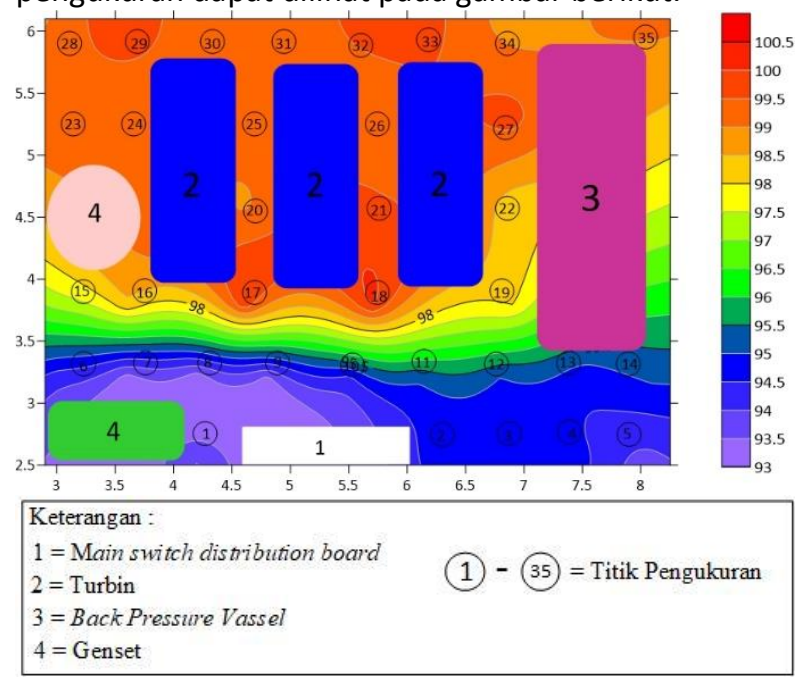

Berdasarkan gambar kontur tingkat kebisingan pada stasiun kamar mesin, dapat dilihat bahwa area sekitar turbin memiliki tingkat kebisingan paling tinggi. Disarakan untuk tempat duduk operator diletakkan di area yang warna biru atau ungu muda.

\section{Kesimpulan}

Berdasarkan hasil penelitian dan pembahasan yang telah diuraikan pada bab sebelumnya maka dapat disimpulkan sebagai berikut:

1. Berdasarkan pengukuran tingkat kebisingan di 35 titik pengukuran selama 5 hari pada stasiun kamar mesin, maka didapatkan kebisingan rata-rata adalah 97Dba. Tingkat kebisingan tertinggi disebabkan oleh 3 unit mesin turbin yang bekerja pada stasiun kamar mesin.

2. Berdasarkan analisis deskriptif dapat disimpulkan bahwa tingkat kebisingan di stasiun kamar mesin pada Pabrik Kelapa Sawit (PKS) PT. Perkebunan Nusantara IV Kebun Adolina Perbaungan melewati Nilai Ambang Batas (NAB) yang telah ditetapkan oleh pemerintah Kep-51/MEN/1999 yaitu 85 dB.

\section{Daftar Pustaka}

[1] C. I. Erliana and R. Rajagukguk, "ANALISA POSTUR KERJA DENGAN MENGGUNAKAN METODE RAPPID UPPER LIMB ASSESSMENT ( RULA ) PADA PEKERJA BAGIAN MOTHER PLANT DEPARTEMEN NURSERY," in Seminar Nasional Teknik Industri [SNTI2017], 2017.

[2] Bakhtiar, C. I. Erliana, and W. Dermawan, "Work time measurement analysis with indirectly working measurement method on cement bagging station," in IOP Conference Series: Materials Science and Engineering, 2019, doi: 10.1088/1757-899X/505/1/012141.

[3] M. M. Dr. Capt. H M. Thamrin, "Perencanaan Manajemen Sumber Daya Manusia," Penerbit
[4] B. A. haulian Siboro, "RANCANGAN PERBAIKAN MEJA KERJA DENGAN METODE QUICK EXPOSURE CHECK (QEC) DAN ANTROPOMETRI DI PABRIK TAHU SUMEDANG," Conf. Senat. STT Adisutjipto Yogyakarta, 2016, doi: 10.28989/senatik.v2i0.78.

[5] S. Alwi, "Manajemen Sumber Daya Manusia Strategi Keunggulan Kompetitif," BPFE UGM, Yogyakarta., 2011.

[6] A. Isvandiari et al., Manajemen Sumber Daya Manusia. 2012.

[7] M. S. P. Hasibuan, "Manajemen Sumber Daya Manusia," Ed. Revisi Jakarta Bumi Aksara, 2011.

[8] I. Nuryasin, M. Musadieq, and I. Ruhana, “PENGARUH LINGKUNGAN KERJA DAN MOTIVASI KERJA TERHADAP KINERJA KARYAWAN (Studi pada Karyawan Perusahaan Daerah Air Minum (PDAM) Kota Malang)," J. Adm. Bisnis S1 Univ. Brawijaya, 2016.

[9] P. Lestari and A. Sriathi, "PENGARUH PELATIHAN KERJA, LINGKUNGAN KERJA FISIK SERTA MOTIVASI TERHADAP PRODUKTIVITAS KERJA PEGAWAI PADA PT. TASPEN (PERSERO) KANTOR CABANG DENPASAR," E-Jurnal Manaj. Univ. Udayana, 2013.

[10] N. Fanny, "Jurnal Ilmiah Rekam Medis dan Informatika Kesehatan 51," J. IIm. Rekam Medis Dan Inform. Kesehat., 2015.

[11] F. E. Budi Setyawan, "PENERAPAN ERGONOMI DALAM KONSEP KESEHATAN," Saintika Med., 2012, doi: 10.22219/sm.v7i1.1085.

[12] E. Cintia and A. Gilang, "PENGARUH LINGKUNGAN KERJA FISIK DAN NONFISIK TERHADAP KINERJA KARYAWAN PADA KPPN BANDUNG I," J. Sosioteknologi, 2016, doi: 10.5614/sostek.itbj.2016.15.1.12.

[13] Nurwati, "Pendeteksi Tingkat Kebisingan Dan Pemberi Peringatan Pada Perpustakaan Berbasis Arduino," Semin. Nas. R., 2018.

[14] D. Abdullah and R. Hardi, "Sistem Tracer Paket Pada Unit Processing Center Pos Indonesia (Persero) Menggunakan Metode Travelling Sales Person Problem," Inform. Mulawarman J. IIm. Ilmu Komput., 2013.

[15] J. Babba, "Hubungan antara intensitas kebisingan di lingkungan kerja dengan peningkatan tekanan darah," Semarang Univ. Diponegoro Semarang, 2007.

[16] C. I. Erliana, D. Irwansyah, D. Abdullah, M. Zarlis, and E. Elviwani, "ANALISIS TINGKAT KEBISINGAN PADA DEPARTEMENT FIBER LINE DI PT. TOBA PULP LESTARI," TECHSI - J. Tek. Inform., 2018, doi: 10.29103/techsi.v10i2.842.

[17] C. Willard, "Chi-Square," in Statistical Methods, 2019. 